\title{
Erratum to: An extract of Melia toosendan attenuates endothelin- 1-stimulated pigmentation in human epidermal equivalents through the interruption of PKC activity within melanocytes
}

Hiroaki Nakajima $\cdot$ Yuki Wakabayashi $\cdot$

Kazumasa Wakamatsu · Genji Imokawa

Published online: 12 April 2013

(c) Springer-Verlag Berlin Heidelberg 2013

Erratum to: Arch Dermatol Res (2011) 303:263-276

DOI 10.1007/s00403-011-1143-y

The author regretted their error in Figs. $2 \mathrm{c}$ and $3 \mathrm{a}$ on the published article. The corrected Figs. 2 and 3 are presented below.

The online version of the original article can be found under doi:10.1007/s00403-011-1143-y.

H. Nakajima · Y. Wakabayashi · G. Imokawa $(\bowtie)$

School of Bioscience and Biotechnology,

Tokyo University of Technology, 1404-1 Katakura,

Hachioji, Tokyo 192-0982, Japan

e-mail: imokawag@dream.ocn.ne.jp

K. Wakamatsu

School of Health Sciences, Fujita Health University,

Toyoake, Japan 
Fig. 2 a Inhibitory effect of the Melia toosendan extract on EDN1-stimulated pigmentation in human epidermal equivalents. Human epidermal equivalents were cultured at $37^{\circ} \mathrm{C}$ for 14 days in DMEM supplemented with $10 \mathrm{nM}$ EDN1, with or without the Melia toosendan extract at concentrations of 2,5 or $10 \mu \mathrm{g} /$ $\mathrm{ml}$. The media were exchanged every 2 days. b HE and Fontana Masson staining and HPLC analysis of eumelanin content in Melia toosendan extract-treated human epidermal equivalents. $a \mathrm{HE}$ and FM staining at day 14 $b$ Eumelanin content at day 14 . Human epidermal equivalents were cultured at $37^{\circ} \mathrm{C}$ for 14 days in DMEM supplemented with $10 \mathrm{nM}$ EDN1 with or without the Melia toosendan extract at a concentration of $10 \mu \mathrm{g} / \mathrm{ml}$. The media were exchanged every 2 days. Melanins produced in the epidermal equivalents at day 14 were subjected to chemical analysis as detailed in the "Materials and methods". Eumelanin content is estimated by quantitation of the pyrrole2,3,5-tricarboxylic acid (PTCA) derivative. $n=3, * p<0.05$. c Immunohistochemistry with anti-S-100 protein at day 14 . $a-c$ Immune staining with anti$\mathrm{S}-100$ protein as red color at day 14. $d-f$ Merged images (as yellow color) with DRAQ5 as green color. Sections were immunostained with anti-S-100 protein and double-stained with DRAQ5 as detailed in "Materials and methods"
A

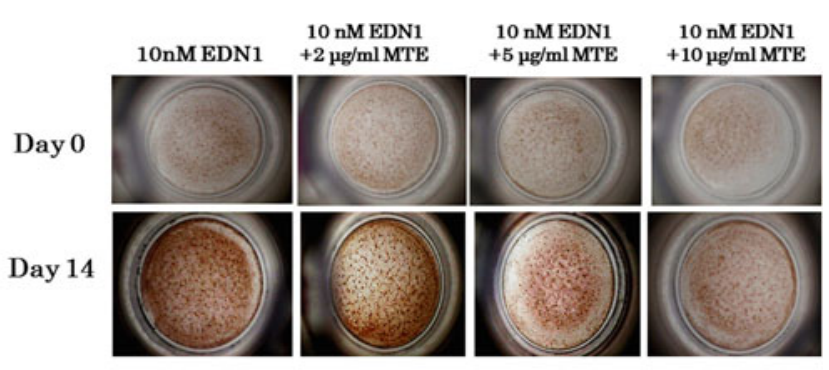

B
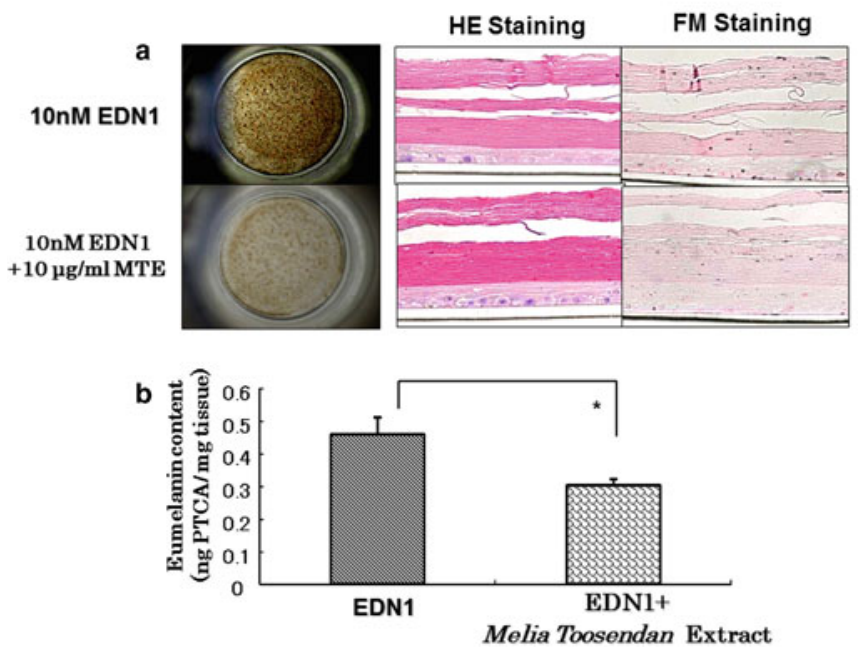

C

Day 14
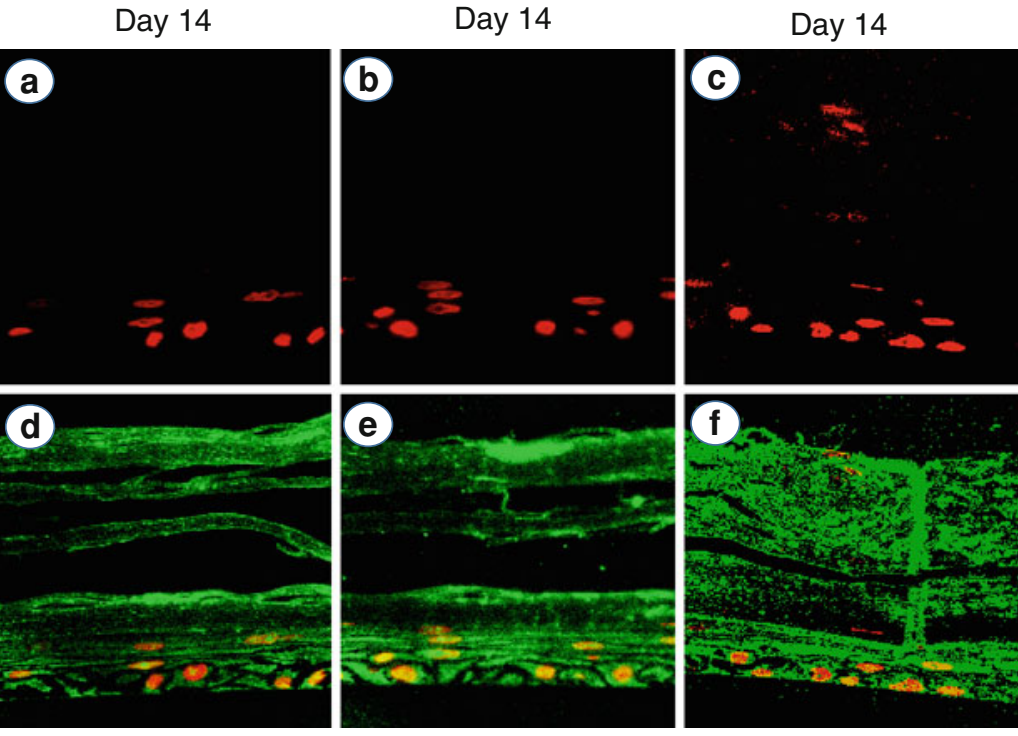

EDN1(-)

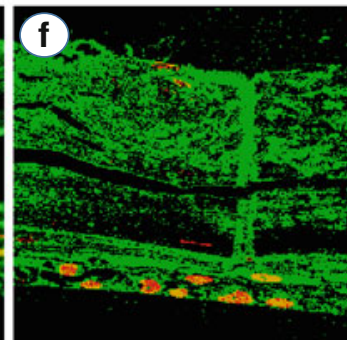

EDN1+MTE(10ug/ml)
Anti-S-100 + DRAQ5 (Merge)
Control

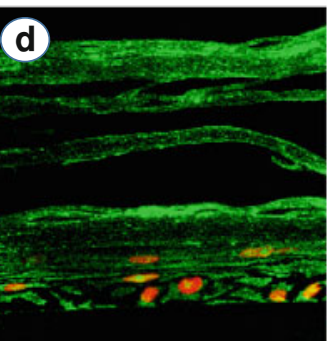

EDN1(10nM) 


\section{A}

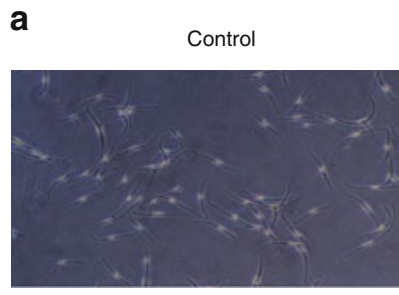

MTT assay $:$ Cell Survival $=100.0 \%$

C

EDN1(10 nM)

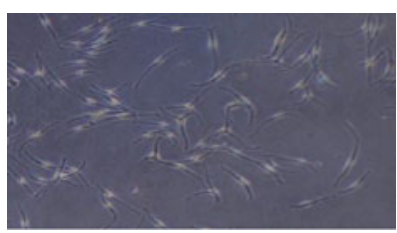

MTT assay $:$ Cell Survival $=100.0 \%$ b Melia Toosendan Extract

$(10 \mu \mathrm{g} / \mathrm{ml})$

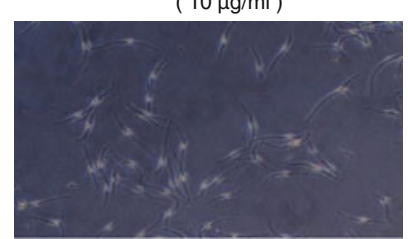

MTT assay $:$ Cell Survival $=92.2 \%$

d

EDN1(10 nM)

+Melia Toosendan Extract

$(10 \mu \mathrm{g} / \mathrm{ml})$

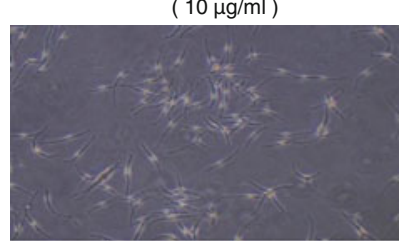

MTT assay $:$ Cell Survival $=90.8 \%$

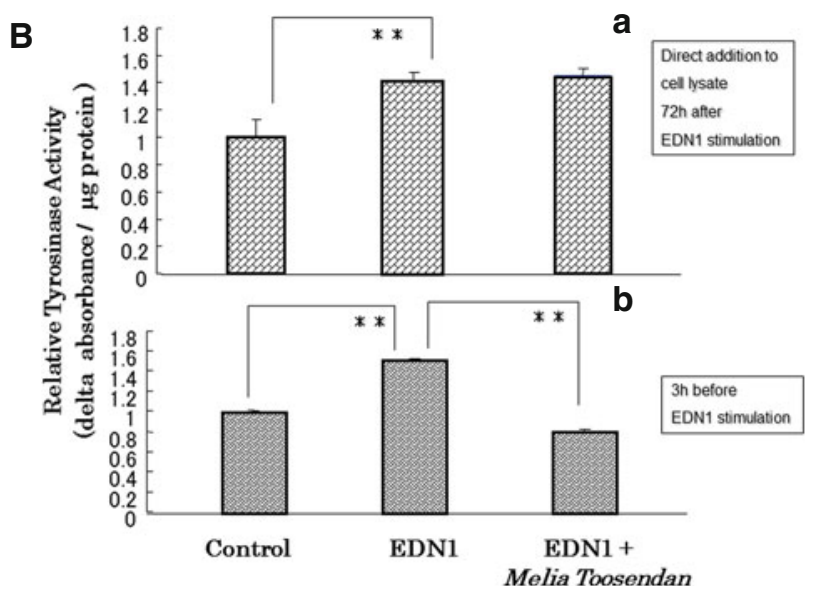

Fig. 3 Effect of the Melia toosendan extract on cell viability (a) and on tyrosinase activity (b). NHM were cultured for $72 \mathrm{~h}$ after EDN1 stimulation together with $3 \mathrm{~h}$ pre-incubation with the Melia toosendan extract at a concentration of $10 \mu \mathrm{g} / \mathrm{ml}$ after which cell viability was evaluated by cellular morphology and MTT assay (a) and the cell lysates were measured for tyrosinase activity $(b)$. In separate experiments, lysates of NHM cultured in the absence of the Melia toosendan extract for $72 \mathrm{~h}$ after EDN1 stimulation were directly incubated with the Melia toosendan extract at a concentration of $10 \mu \mathrm{g} / \mathrm{ml}$ after which tyrosinase activity was measured, as described in "Materials and methods" in lysates of NHM (b). a $a$ Control, $3 \mathrm{~h}$ after the mock addition, $b$ Melia toosendan extract, $3 \mathrm{~h}$ after the addition, $c$ EDN1, $72 \mathrm{~h}$ after EDN1 stimulation, $d$ Melia toosendan extract + EDN1, $72 \mathrm{~h}$ after EDN1 stimulation. $\mathbf{b} a$ directly added to cell lysate after being cultured for $72 \mathrm{~h}$ in the presence of EDN1, $b$ added $3 \mathrm{~h}$ before EDN1 stimulation and cultured for $72 \mathrm{~h}$ in the presence of EDN1. $n=3, * * p<0.01$ 